\title{
«Traición en la amistad» de María de Zayas
}

\author{
SUSAN PAUN DE GARCÍA \\ Denison University
}

La única obra de teatro escrita por María de Zayas que conocemos es la Traición en la amistad, publicada primero por Serrano y $S_{\text {Sanz }}{ }^{1}$, y editada recientemente por Alessandra Melloni ${ }^{2}$. Advierte Melloni que, contrariamente a lo afirmado por Paz y Meliá de que la obra era "autógrafa y firmada" parece ser, como hizo notar primero Serrano y Sanz, "un manuscrito de mediados del siglo XVII; es copia bastante defectuosa; parece ser que el amanuense era andaluz, por la frecuente conversión de la c en s" ${ }^{3}$. La edición de Melloni corrige algunos de los errores de transcripción hechos por Serrano y Sanz, y también aclara dudosas atribuciones del diálogo así como cuestionables interpolaciones de versos o de fragmentos de versos que faltan.

1. Manuel Serrano y Sanz, Apuntes para una biblioteca de escritoras españolas, II, Madrid, 1905, pp. 583-587. Véase p. 590. La edición de Serrano y Sanz está basada en un manuscrito de la colección del duque de Osuna, ahora en la Biblioteca Nacional de Madrid (Res/173): "Comedia famossa / de la trayción en la amis/tad». Para una visión general sobre María de Zayas véase el estudio completísimo de Salvador Montesa Peydro, Texto y contexto en la narrativa de María de Zayas, Madrid, Dirección general de la Juventud y Promoción Sociocultural, 1981. También es muy valiosa la introducción de Alicia Yllera a su edición crítica de los Desengaños amorosos, Madrid, Cátedra, 1983. Véase también Feminismo y forma narrativa de Sandra Foa, Valencia, Albatros, 1979.

2. Verona, Università, 1983.

3. Melloni cita a Serrano y Sanz, p. 5. 
Melloni fecha la obra entre 1618 y 1620 , basándose en dos hechos. En primer lugar, es posible que Traición en la amistad sea la "comedia de excelentes coplas" a la que se refería Montalbán en Para todos; de ser así, ésta se habría completado necesariamente antes de 1632, cuando apareció Para todos. En segundo lugar, Melloni advierte la presencia de versos sueltos en la comedia de Zayas, que para ella parece indicar una fecha más cercana a 1620 como el terminus ad quem: "Como è noto, grazie a una serie di studi; i sueltos spessiggiano nel teatro del Seicento fino alla prima decade del secolo, per poi diminuire e scomparire quasi totalmente dopo el $1620 n^{4}$. Encuentro un tanto dudosa la fecha propuesta por Melloni por varias razones. Primero, volviendo a la referencia de Montalbán, me parece significativo que diga que María de Zayas «tiene acabada [el subrayado es mío] una comedia...". Para mí esto sugiere una fecha de conclusión de Traición en la amistad más cercana a la de Para todos (1632). Las primeras noticias que tenemos de la carrera literaria de María de Zayas son hacia 1621, cuando contribuye con un soneto a los poemas laudatorios preliminares en la obra de Miguel Botello, La fábula de Piramo y Tisbe. Podemos estar completamente seguros de que por aquella fecha estaba escribiendo poesía activamente, pero no hay ninguna mención de que Zayas escribiese comedias hasta que lo menciona Montalbán once años más tarde.

De modo semejante, si seguimos el criterio de Morley y Bruerton para fechar las obras de Lope y se lo aplicamos a Zayas, nos inclinaremos también a buscar una fecha más tardia ${ }^{5}$. Después de examinar los tipos de versos usados por Zayas, hallaremos, entre otros, romances $(52,2 \%)$, redondillas $(10,1 \%)$, sonetos $(3,4 \%)$, silvas, tipo $2(5,4 \%)$, quintillas $(3,3 \%)$, tercetos $(1,1 \%)$ y décimas $(1,3 \%)$.

Algunos de éstos no nos sirven para determinar la cronología mientras que otros indican el periodo de 1630 a 1635 como muy probable. Un porcentaje de romances similarmente alto se da en las obras de Lope de Vega entre 1630 y 1635 (49\%-55\%) y silvas del tipo 2 (5\%-10\% entre 1627?-1635). Sin embargo hay unos porcentajes comparables de quintillas y tercetos entre 1588 y 1635 , lo cual no nos ayuda mucho a fijar una fecha probable. Naturalmente, es arries-

4. Melloni, p. 8.

5. Me refiero a S. Griswold Morley y Courtney Bruerton, The chronology of Lope de Vega's Comedias, Nueva York, MLA y Oxford University Press, 1940, y especialmente a la sección «Tabular Views", pp. 120-124. 
gado aplicar a otro autor datos válidos para Lope de Vega, a pesar del hecho de que María de Zayas fue de la "escuela de Lope». Sin embargo parece tan válido como la conclusión de Melloni, si no más convincente.

La comedia española del siglo XVII tenía unas características básicas que fueron observadas por todos los que trataron de escribirlas: tres actos, polimetría, un elenco de personajes fijos y, con frecuencia, un argumento secundario. Lope convirtió estas características en normas que rigieron hasta bien entrado èl siglo XVIII ${ }^{6}$. Traición en la amistad está dividida en tres jornadas: la primera tiene 862 versos y 10 cambios de metro, la segunda 935 versos y 14 cambios, y la tercera 1.117 versos y 17 cambios de metro ${ }^{7}$. De acuerdo con las convenciones del género, la primera jornada presenta el conflicto, la segunda el enredo y la tercera el desenlace.

Traición en la amistad podría clasificarse como una comedia de enredo o de capa y espada ${ }^{8}$. El argumento principal gira en torno al amor, o de modo más específico, al amor frente a la amistad. Pero es difícil determinar donde acaba el argumento principal y donde comienzan los secundarios, ya que los conflictos se entrecruzan a lo largo de la obra.

El engaño causado por el amor y sus efectos sobre la amistad sostienen la intriga de la comedia de Zayas. El amor es el tema o motivo principal, y su manifestación dramática puede expresarse en términos de oposición: amor frente a amistad, y amor frente a honor. Naturalmente, el amor va acompañado por los $\operatorname{celos}^{9}$ y la acción avanza a través del engaño. Lo interesante de esta comedia es que estos temas se manifiestan en el ámbito de los personajes femeninos, es decir, la amistad entre las damas y el honor de las damas.

La estructura de la comedia incluye cuatro damas, cuatro galanes -todos nobles- además de un gracioso y de una criada. Se van

6. Edward M. Wilson y Duncan Moir, A Literary History of Spain, The Golden Age: Drama 1492-1700, Nueva York, Barnes \& Noble, 1971, p. 43.

7. Para un esquema métrico detallado véase Melloni, pp. 12-14.

8. Wardropper, La comedia española del siglo de oro, Barcelona, Editorial Ariel, 1978, p. 194.

9. «Según la convención teatral, [los celos] van indisolublemente ligados al amor, del que constituyen la prueba, especialmente, para la damam. Véase Charles Vincent Aubrun, La comedia española (1600-1680), Madrid, Taurus, 1968, p. 235. 
añadiendo otros personajes para hacer avanzar la acción, aclarar la intriga o proporcionar música ${ }^{10}$. Los personajes, tal y como esperaríamos hallarlos emparejados al final, son:

\begin{tabular}{llll} 
Damas & Galanes & Gracioso/Criada \\
\cline { 1 - 1 } Marcia & & Gerardo & \\
Belisa & D. Juan & León = Lucía \\
Fenisa & Liseo &
\end{tabular}

Los restantes personajes son Felis, el paje de Laura, y Antonio y Fabio, músicos. Aunque se menciona a Leonardo, el anciano guardián de Laura (verso 1043), éste no aparece nunca en escena.

En el acto I se presentan unos problemas, y las complicaciones continúan hasta llegar al clímax, muy avanzada ya la tercera jornada. Entonces se produce un alto -una serie de comentarios, una fábula y una escena de amor- antes del desenlace. Aunque al final quedarán reunidas, las parejas comienzan el primer acto en una situación caótica, separadas por el enamoramiento de la dama o el galán de una tercera persona; la acción va encaminada a emparejar a cada uno con quien le corresponde y a castigar a los causantes del caos ${ }^{11}$.

Estos últimos son Liseo y Fenisa. Liseo ya ha gozado los favores de Laura bajo promesa de casarse con ella pero es un inconstante, y cuando se alza el telón está cortejando a Marcia. Desde el principio no solamente rechaza a su prometida sino que impide a Gerardo alcanzar sus deseos. Por su lado Fenisa, al ver el retrato de Liseo, se enamora de él, y así nace un conflicto entre su amor por el galán y su amistad con Marcia. Pero el amor puede más, y Fenisa intenta persuadir a Marcia de que renuncie a Liseo. La rabia de Marcia al reconocer las estratagemas de Fenisa efectivamente rompe la amistad entre las dos.

10. Para una visión general del tema, véase Juana de José Prades, Teoría sobre los personajes de la comedia nueva, en cinco dramaturgos, Madrid, C.S.I.C., 1963. Véase en especial pp. 251-263.

11. Según Melloni, la estructura del conflicto puede verse como el de la pareja de amantes amenazada por la intervención de otra mujer, como era frecuente en las novelas de Zayas. Sin embargo aquí las parejas son varias y la "otra mujer" amenazadora es la misma en todos los casos. Véase Melloni, p. 15. Creo que el pasar por alto el efecto disruptivo de Liseo simplifica demasiado la estructura ya que constituye el tercer elemento del triángulo Marcia-Gerardo-Liseo, y provoca la traición en la amistad de Marcia y Fenisa que forma el eje de la acción. 
Según se desarrolla la obra es evidente que Liseo y Fenisa se revuelven cada vez más en el fango del engaño. Al verse forzada a escoger entre amistad y amor, Fenisa apenas vacila. Decide conquistar a Liseo, y descubrimos que ya lo hizo con el don Juan de Belisa, y luego trata de añadir a Gerardo y a Lauro a su grupo de admiradores. Cambia de amantes con la misma facilidad con que cambia de ropa, y con todos se muestra enamorada y cariñosa. Los engaña porque no lo queda otro remedio; los quiere a todos pero como la sociedad no permite tal cosa, Fenisa tiene que engañar. Para ella, el amor es un deseo irresistible de controlar y de poseer a los hombres, sin que favorezca a ninguno en particular.

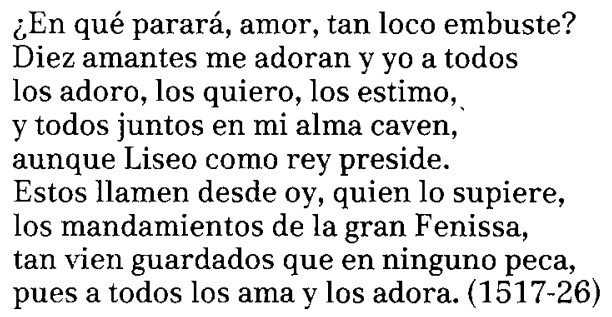

Por otra parte, Liseo se daría tan solo a una mujer, pero no tiene escrúpulos en engañar a otra para pasar el rato. Su mayor pecado ha sido abandonar a Laura. Sabe que está mal «que tú eres la causa desto / y de que yo mi palabra / quiebre a Dios, a Laura, al mundo" (1381-83), pero no puede o no quiere arrepentirse. Aunque le gusta compartir el lecho de Laura, le molestan y cansan los celos y las importunidades de ésta, lo que acaba beneficiando a Marcia. Dice que ha terminado con Laura pero no cambia de conducta. Cuando Fenisa le declara su amor, Liseo decide coquetear con ella aunque no deja de cortejar "seriamente» a Marcia: "Divina Marcia, perdona / si en no ser leal te ofendo, / que a Fenisa boi a ver, / y aun a engañarla, si puedom. (610-13).

Ni Fenisa ni Liseo hallan ventajas en limitar sus amores y no quieren o no son capaces de hacerlo. Según las normas de la comedia, estos personajes tendrán que cambiar o serán castigados, pues son malos ejemplos que representan una conducta reprensible.

Con ellos contrastan otros personajes que son paradigma del amor y de la amistad. Gerardo es un amante fiel y ejemplar que no ceja en su empeño a pesar de que pretende sin esperanzas desde hace siete años: "Qual Jacob querré otros siete, / si he de gozar a Ra- 
quel» (644-45). Continúa fiel e incluso se enfada cuando se le acerca Fenisa con proposiciones deshonestas:
¿Calla, lengua de serpiente, calla, amiga destos tienpos!
Calla, desleal, y advierte
que he de adorar aquel ángel:
jamas mi fe se arrepiente
de un ángel, de un serafín.
$¿$ Con aquesa lengua aleve
osas hablar y yo escucho
tal, sin cortarla mil vezes?
Por ser mujer Marçia bella
y dever a las mugeres
sólo por ella respeto,
será mejor que te deje. (1570-82)

Marcia es la dama ejemplar y aunque está prendada de Liseo, renuncia a él por completo cuando se entera de que está ya comprometido con otra (994-1006). Marcia valora la amistad y el honor de una mujer más que la atracción que siente por Liseo. Es, sin duda, la que mayor fuerza moral tiene de todos los personajes. A ella se debe la idea del engaño-venganza armado para castigar a Liseo y devolver a Laura su honor; tercia en una disputa entre Belisa y Fenisa; y pronuncia la sentencia final contra ésta última.

La mayor parte del diálogo amoroso no tiene lugar, sin embargo, entre ninguno de estos personajes, sino entre Belisa y don Juan. Aunque éste estuvo por un tiempo encaprichado de Fenisa, Belisa le reprende y le hace cambiar de conducta. Su enojo reaviva el amor de don Juan y a esta pareja se deben algunas de las mejores escenas amorosas de la comedia.

Laura, la dama restante, sirve de "castigo" a Liseo, y la demanda y reivindicación final de su honor vuelven a poner las cosas en su sitio. De manera semejante, Lauro, el último galán, "castiga» a Fenisa. Al final de la obra todos quedan emparejados con excepción de Lauro, a quien debería haber correspondido Fenisa. Al fin, él reconoce sus engaños y aunque ama a Fenisa, acaba por rechazarla: "...yo te amaba, / no te aborrezco, mas al fin te dexo" (2448-49).

Todas estas damas son muy resueltas cuando es necesario aunque hayan sido incapaces de resistir la subyugadora fuerza del amor. Laura lo fue tanto que perdió la virginidad y, en consecuencia, el honor. El matrimonio con el que podría recobrarlo es impedido por Marcia y Fenisa, sus sucesoras en el corazón de Liseo. Como sus rue- 
gos no causan mella en el ánimo del galán, Laura presenta su caso a la dama: "Marçia, dame tu consejo, / que si Liseo se cassa, / vien bes quan perdida quedo" (1028-30), Marcia renuncia a Liseo de inmediato, generosamente y sin vacilar pues para ella están primero el honor y la amistad.

Las damas se solidarizan en su deseo de venganza; Belisa lo hará por sí sola mientras Marcia y Laura se vengarán juntas. Marcia ha vuelto a la cordura y puede así proporcionar la inspiración y los medios para resolver el conflicto y cuando hable su voz será la de la razón. De hecho, su función es la misma que la de la figura del rey en la comedia: ser árbitro, juez, restaurador del honor y del orden. En comparación con ella, Laura es débil, desvalida y desorientada. Como infinidad de las víctimas/heroínas de las Novelas amorosas y ejemplares y los Desengaños amorosos, es joven y huérfana:

\author{
Mis padres, que el cielo goçan, \\ me faltaron a tal tiempo \\ que cassi no conozí \\ a los que vida me dieron; \\ quedé niña, sola y rica, \\ con un noble caballero \\ que tubo gusto en criarme, \\ por ser de mi madre deudo. (959-65)
}

Ha permitido que se aprovechen de ella y continúa haciéndolo hasta llegar a punto de perderse para siempre. La restauración de su honor exige el matrimonio con el que se lo quitó. Al principio le ayuda Felis, quien sigue a Liseo y descubre así quien es Marcia y donde vive. Sin embargo, Marcia es quien salva a Laura, y Marcia es quien discurre el plan para engañar a Liseo. El plan funciona porque éste piensa que corteja a Marcia cuando es Laura quien está detrás de la reja. Una y otra vez Laura teme hablar y tomar determinaciones y solamente en el último acto recrimina vehementemente a Liseo, enloquecida por la desesperación: "Cierra essa ynfame boca, / que no es quimera, no, traydor, mi queja” (2046-47). Incluso entonces habla amparándose en un disfraz.

Pero la envalentona Marcia y es evidente que todas las mujeres deberían tomar a Marcia como ejemplo. De manera semejante Belisa decide recobrar a su galán después de que Marcia declara que Fenisa ha de ser castigada por su Traición en la amistad. Todas determinan volver por lo suyo y a la vez defender su amistad.

Fenisa es la única dama que ni evoluciona ni cambia. Desde el 
principio reconoce sus errores pero gusta de ellos: «Aunque a don Juan digo amores / el alma en Liseo está, / que en ella posada abrá / para un millón de amadores» (189-92). Es evidente que las «leyes» del amor no admiten al corazón una pluralidad de amantes y en eso Fenisa va en contra de ellas. Pero por otra parte, cuando sus pretendientes dan señales de abandonar sus galanteos, los celos de Fenisa dan fe a la sinceridad de sus sentimientos. Es una egoísta impúdica; no respeta ni los derechos de posesión previa de sus amigas ni observa las obligaciones que crean tales amistades. No quiere ser de otra manera; rechaza consejos y persiste en sus intrigas aun a sabiendas de que todos conocen ya sus artimañas:

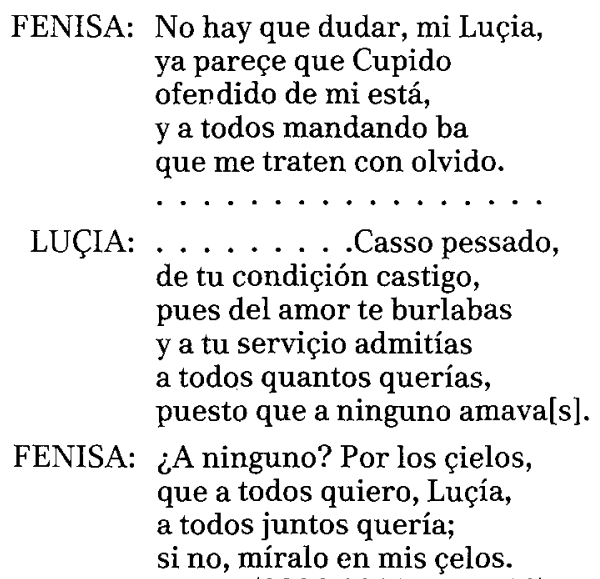

(2296-2300, 2307-16)

Con resolución y en repetidas ocasiones rechaza someterse a las normas establecidas y por ello ha de ser castigada.

Al comenzar la obra, los galanes aparecen como más débiles y, con excepción de Gerardo, todos están enamorados de Fenisa, signo de vulnerabilidad y falta de sentido. Se diria que no son capaces de resistir a sus encantos a pesar de la fe debida a las propias damas de cada uno. Don Juan resulta cansino en su celosa sumisión a Fenisa, y más tarde Lauro cae también en sus redes. Pero ambos galanes recobrarán la razón: Don Juan reconoce que su verdadero amor es Belisa y aun restaura su honor; Lauro ama a Fenisa pero también vuelve en sí y la rechaza por obrar de modo tan engañoso.

Liseo es algo más complejo. Aunque en el pasado amó a Laura, se cansó de ella y su hastio ha llegado a borrar su sentido del deber 
aunque egoístamente ha mantenido sus relaciones con Laura para gozarla por las noches. Tan censurable actitud empeora cuando decide compartir sus atenciones amorosas con Marcia, y luego para entretenerse, con Fenisa. En el tercer acto, cuando las cosas comienzan a ponerse mal, da muestras de arrepentirse e incluso de anhelar a Laura:

\author{
Oh, Laura, tus maldiçiones \\ me alcançen, pues sin razón \\ traté tan mal tu afición, \\ olvidando obligaçiones. \\ si Laura no hubiera dado \\ santo fin a su afiçión, \\ cunpliera mi obligaçión \\ a su firmeza obligado $(1957-60,1969-72)$
}

Es claro que el «castigo» de reunirse con su prometida no le resultará severo; es más, el engaño que Marcia y Laura llevan a cabo resulta irónicamente innecesario.

El único personaje, masculino o femenino, que es constantemente positivo es Gerardo. Tiene una constancia bíblica, resiste indignado a Fenisa, y su premio es la ejemplar Marcia.

León y Lucía son personajes secundarios que sirven como figuras de donaire y para aconsejar a sus amos. Lucía ayuda a Fenisa en sus campañas amorosas aunque no está de acuerdo con ellas. León, el gracioso típico, está más delineado y hace gala de humor basto a lo largo de la obra. Los intrincados enredos tienen como contrapartida el humor indecente, los porrazos bufonescos, las borracheras e incluso la sátira política que ofrece el gracioso. Algunas escenas son francamente divertidas. El panegírico que hace León de las fregatices gallegas (303-349), además de tener gracia, es todo lo opuesto a la idea caballeresca que tiene Lisardo de la mujer ideal:

\footnotetext{
Pareçe que estás loco; ¿para qué quieres castas ni Dianas?

Anda, señor, parezes boquirrubio;

¿para qué quiero yo mugeres castas?

Mejor me hallara si castiza fuera
}

(357-61)

En algunas ocasiones las muelas del gracioso pagan las iras ajenas (1309-1463). Con León, la acción desciende a su nivel más bajo y su franqueza contrasta humorísticamente con los engaños y las tretas de los personajes nobles. No solamente critica a su amo sino a la cla- 
se a la que pertenece, sus maneras de cortejar (288-299) o su modo de vestir cortesano (2533-2628). Al concluir la obra, él tiene la última palabra.

Si la acción determina el carácter, de manera semejante el tema da forma a la acción. En Traición en la amistad se da, naturalmente, el anunciado tema de la amistad frente al amor. El conflicto entre ambos lleva al engaño, no solo por parte de Fenisa sino por la de Laura y Marcia también. El engaño de Fenisa se presenta de modo negativo pues ésta es una especie de don Juan femenino para quien el amor y el engaño van entrelazados ${ }^{12}$. Con ayuda de Marcia, a Laura no le queda otro remedio que mentir para recuperar su honor ya que su sinceridad tan sólo ha intensificado sus problemas con Liseo. Marcia prepara el engaño en parte para defender la justa causa de Laura pero también para vengar la traición de su falsa amiga Fenisa. Al parecer, los hombres engañan porque ese es su modo de ser. Son inconstantes pero luego vuelven a su primer amor, con más o menos entusiasmo.

$\mathrm{Al}$ amor y la amistad corresponden otros temas secundarios en esta obra. Las damas conciben el amor como una fuerza platónica y ennoblecedora. En la escena inicial, Marcia describe el enamoramiento como un proceso en el que el amor llegase al alma a través de los ojos, ennobleciéndola:

Puso los ojos en mí
y en ellos mismos me ynbía
aquel beneno que dizen
que se bebe por la vista;
fueron los míos las puertas,
pues con notable ossadía
se entró por ellos al alma,
sin respetar a sus niñas.
Siguióme y supo mi cassa,
y por la nobleza mía
apareçió el çiego lazo
que sólo la muerte quita;
soliçitóme amoroso,
hizo de sus ojos çifras
de las finezas del alma,
ya por mil partes perdida.

12. En su artículo sobre esta comedia, «Love, Friendship, and Deceit in La traición en la amistad, by María de Zayas", Matthew Stroud ve una dimensión de vengadora en Fenisa, pagando los engaños de los hombres en la misma moneda. Véase Neophilologus 69 (1985), 539-547, pp. 542-3. 
Al mismo tiempo, los ojos de Liseo tienen para Fenisa no una fuerza ennoblecedora sino un poder irresistible y hechicero, peligro del cual se da cuenta:

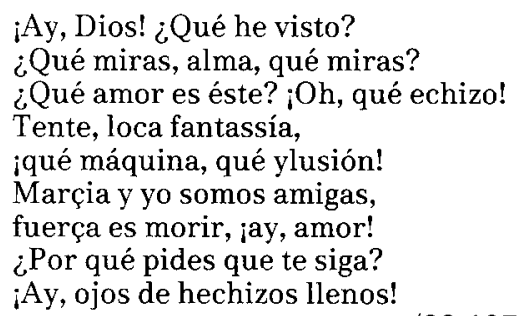

El amor en el sentido de amistad también penetra por los ojos. Laura, al conocer a Marcia y a Belisa, queda subyugada por la belleza de su rival. Su intercambio de lisonjas deja ver que la belleza hace en ellas el mismo efecto que en los hombres (915-20). Además, el amor -es decir, la amistad-entre mujeres tiene sus propias obligaciones, que la nobleza les obliga a cumplir (936-40). Consecuentemente el tema de la amistad está relacionado con el del honor y la venganza. Las mujeres ven el honor como la virtud o su apariencia. Laura es la única que ha perdido el honor, pero como nadie lo sabe ella tiene buen cuidado de guardar las apariencias:

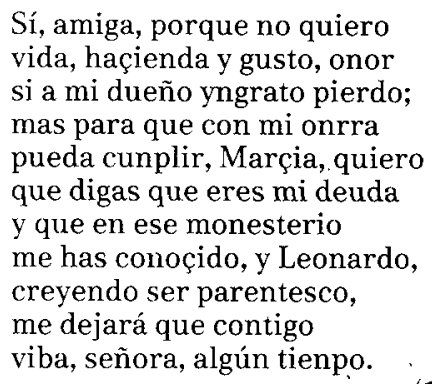

(1036-46)

Belisa y Marcia quieren vengarse principalmente porque Fenisa las ha puesto en ridículo y lo hacen conquistando de nuevo a don Juan y a Liseo (Marcia obra por Laura). Fenisa abusa de todos de un modo tan desconsiderado que está a punto de perder el respeto debido a una dama. Gerardo, el caballero ejemplar (véase 1576-82), mantiene el decorum pero don Juan no; para vengar la falsía de Fenisa está a punto de sacar la daga (1736-75). No lo hace porque la sangre habría dignificado las faltas de ésta. Le da una bofetara para ultrajar 
su honor: "Así se castiga / a las mugeres que yntentan / desatinos semejantes / y que a los hombres enredan" (1748-51). Irónicamente, la misma Fenisa pide venganza al darse cuenta de que todos sus pretendientes la han abandonado: "Yo he de bengarme, / Luçía, no hay que tratar; / yo los tengo de matar, / no tienes que aconsejarme" (2325-29).

De hecho, la ironía se usa en toda la obra. Ya en la primera escena, Fenisa da consejos a Marcia que ella misma debería seguir (44-58). Laura piensa que Liseo tan sólo coquetea con Marcia pero que ama a Fenisa cuando en realidad ocurre todo lo contrario (1023-30). Liseo se lamenta de que Laura haya entrado en un convento y así no pueda casarse con ella, como debería haberlo hecho antes, sin saber que Laura no ha tomado los votos y que acabará siendo su esposa. Y al final, Fenisa pide justicia sin darse cuenta de cuán justiciero ha sido su castigo.

El propósito moral de esta obra, coronado por la justicia poética del desenlace, es prevenir a las mujeres contra el comportamiento de gentes como Fenisa. Zayas alcanzará fama por su defensa de la mujer contra los engaños de los hombres, pero en esta obra aconseja a las de su propio sexo que no tendrán motivos para quejarse si ellas usan de los mismos ardides. Incluso Lucía, la criada, se dirige así al público:

Señoras, las que entretienen
tomenen ejenplo en Fenissa,
huyan destos pisaverdes.
Digan, seño. . . . . . . . . . . . . .
en dezir que quiere a todos?
Cossa ynpussible pareze,
mas no quiera una muger
que bive mintiendo sienpre
pedir verdad a los honbres;
neçias serán, si lo creen.

(2473-75, 2480-87)

Indudablemente, Marcia es la figura ejemplar con mayor fuerza moral, y como tal es digna de imitación: «Pues para que egenplo tengas, / mira cómo doi mi mano / a Gerardo porque sea / premiada su boluntad» (2848-51). Y es Marcia quien pronuncia la sentencia final (2897-2904).

Unos cuantos comentarios morales a lo largo de la comedia se refieren a los engaños de los hombres (1637-8, 2066-7). Pero bastan- 
tes más tienen que ver con el triste estado del mundo o "los malos tiempos": "¿Qué piensas sacar de amar, / en tienpo que no se mira / ni belleza ni birtudes, / sólo la hazienda se estima» $(55-58)^{13}$. Y al final, una larga conversación entre Belisa y León, en la que éste hace comentarios sobre los tiempos que corren, ofrece un intervalo humorístico poco antes del desenlace (2545-52).

Aunque la obra trata temas propios de una sociedad de caballeros e hidalgos, no faltan algunos que corresponden a las clases populares, principalmente a través de los criados. León relata anécdotas de mujeres lascivas (388-403) y clérigos licenciosos (558-605), y Lucía cuenta cómo su abuela comparaba a los hombres con los ajos en el mortero:

\begin{abstract}
Así deçía mi agüela, que Dios haya, que avía de ser en número ynfinitos, tantos como los ajos que, puniendo muchos en un mortero [arracimados], salte aquel que saltare, que otros quedan, que si se ba o se muere nunca falte.
\end{abstract}

(1508-1513)

De carácter menos casero y más literario es la receta de un filtro amoroso, en forma de soneto, que recita León (2224-2237). Y la versión de Belisa de la fábula esópica del león con cuartanas es una réplica al gracioso cuando éste critica la Corte; previniéndole así de modo humorístico y de una forma que pueda comprender y apreciar.

Traición en la amistad es la única obra teatral que conocemos de María de Zayas y por ello no podemos comparar esta comedia con otras suyas. Entre sus elementos positivos están el rápido desarrollo de la acción y, especialmente, los personajes León y Fenisa. El primero muestra que Zayas tenía buen sentido de lo cómico (como puede apreciarse más tarde en novelas como El castigo de la miseria, El prevenido engañado, y Al fin se paga todo) y que sabía manejar las réplicas agudas y los apartes. Fenisa es un personaje con garra, obviamente despreciable pero no odiosa del todo. Aunque sus reacciones son cada vez más extremadas y estridentes, nunca llega a ser una caricatura como el don Marcos o la doña Inés en El castigo de la miseria. De

13. También: «iMal haya quien en tal tienpo / tiene amigas!» (1082-3); «calla, amiga destos tienpos!" (1571); "Si acasso has dicho verdades, / no me espanto, que este siglo / la[s]aborreze en todo estremo". (2166-8), etc. 
manera semejante, la ejemplar Marcia tampoco es perfecta ni empalagosa.

Con todo, la Comedia famossa de la traición en la amistad no es obra de un maestro. Tiene muchas faltas, empezando con el tratamiento difuso del tema moral a lo largo de la comedia. Si el propósito didáctico es prevenir a las mujeres contra procederes como el de $\mathrm{Fe}$ nisa, entonces los engaños de Liseo tan solo desvían el enfoque de un tema principal a otro secundario: los engaños de los hombres. Además hay complicaciones innecesarias; así, ¿por qué cuenta Felis a Laura que Liseo se ha casado con Fenisa cuando no es necesario reiterar o establecer de nuevo que Laura está celosa? (1837-1868). También hay pausas abruptas en la acción, como el desmesurado diálogo entre León y Belisa a fines del acto III, inmediatamente antes del desenlace. Las escenas amorosas son pedestres y carecen de la chispa que tienen las de Lope. Sin embargo, Traición en la amistad podría representarse muy bien, sobre todo si se eliminasen o acortasen algunas de las escenas más lentas, como probablemente habría hecho un buen autor de entonces.

No hay evidencia de que la comedia de María de Zayas se llegase a representar nunca en público o en privado. Es posible que hubiese pensado incluirla en las Novelas amorosas y exemplares. El tema habría reforzado el del marco narrativo, en el que Lisarda traiciona la amistad de Lisis al apropiarse las atenciones de don Juan. Es posible que Zayas hubiese hecho circular el manuscrito entre sus amigos literarios, quizás en una academia. Aunque la poesía era el género más leído y más comentado, como el drama se consideraba una extensión del verso, solía comentarse también en las reuniones de aquellos grupos. Sabemos que Montalbán se refirió a una «comedia de excelentes versos" escrita por Zayas pero no podemos dar por sentado que ésta fuese Traición en la amistad. No obstante, la referencia de Montalbán prueba que María de Zayas y Sotomayor no fue escritora que trabajaba en secreto sin darse a conocer. Al contrario, daba a leer sus obras a sus colegas y, animada por sus elogios las llevó a la imprenta. Entonces, ¿por qué no hizo ésto con su comedia, la cual no era peor ciertamente que muchas de las representadas por entonces? Quizás sus contemporáneos la animaron a preferir la prosa. En cualquier caso, no tenemos otra alternativa que la muy poco satisfactoria de la suposición y la conjetura. 